Letrônica, Porto Alegre, v. 7, n. 1, p. 385-400, jan./jun., 2014

\title{
FLANAR E RELER CURITIBA: O OLHAR DERRISOR DE DALTON TREVISAN
}

\author{
TO STROLL AND REREAD CURITIBA: \\ THE SCOFFER LOOK OF DALTON TREVISAN
}

\author{
Jailton Gonçalves Prates* \\ Níncia Cecília Ribas Borges Teixeira**
}

\begin{abstract}
Resumo: 0 presente artigo discute questões pertinentes ao espaço urbano, de maneira específica a cidade de Curitiba, sua disposição (cartografia urbana), seus símbolos e as imagens que emergem a partir do discurso oficial para ratificar no ideário popular conceitos como "cidade modelo", "capital de desenvolvimento", "joia rara" e "capital da sustentabilidade". Esses conceitos serão contestados por meio das narrativas de Dalton Trevisan, que apresentam uma Curitiba sem pinheiros, sem flores e sem monumentos, pois não é sua intenção apresentar essa cidade linda, mas sim uma Curitiba marginal e distópica, povoada por pobres, andarilhos, prostitutas, loucos, enfim, por homens reais, marcados pelas desigualdades, pela fome, dor e angústia. Dalton Trevisan contempla o subúrbio e a miséria do homem, apresentando-o fragmentado, sem esperanças, marginal e explorado. Essas ideias estão dispostas na obra-síntese de Dalton Trevisan, Em busca de Curitiba perdida (1992), publicada por ocasião da comemoração dos 300 anos de fundação de Curitiba, como forma de protesto e para mostrar que a cidade possui dois lados: o centro e a margem e que desta margem ecoa o canto de lamentação da sua Curitiba de antanho. A fim de corroborar as ideias apresentadas e defendidas, este artigo apresenta a análise do conto "Cemitério de Elefantes", que possibilita a visualização de um espaço urbano despudorado, em ruínas e em transformação ininterrupta.
\end{abstract}

Palavras-chaves: Dalton Trevisan; Curitiba; Cidade; Flanêur; Leitura.

Abstract: This paper discusses relevant issues to urban space, specifically the city of Curitiba, its disposal (urban mapping), its symbols and images that emerge from the official discourse to ratify the popular ideas concepts like "model city" , "capital development", "rare jewel" and "capital of sustainability". These concepts will be challenged through the narratives of Dalton Trevisan, who has presented a Curitiba with no pine, no flowers and no monuments, because it is not his intention to present this beautiful city, but a marginal Curitiba and dystopian, populated by the poor, vagrants, prostitutes, crazy people, finally, for real men, marked by inequalities, hunger, pain and anguish. Dalton Trevisan includes the suburbs and misery of man, presenting the fragmented hopelessly marginal and exploited. These ideas are arranged in the work - synthesis of Dalton Trevisan. "Em busca de Curitiba perdida" (1992), published on the occasion of the commemoration of the 300th anniversary of the Curitiba foundation, in a way of protest to show that the city has two sides: the center

\footnotetext{
* Egresso do Curso de Pós-Graduação Stricto Sensu - Mestrado em Letras da Universidade Estadual do Centro Oeste - UNICENTRO. E-mail: pratesig@hotmail.com

${ }^{* *}$ Doutora em Letras pela UNESP (2005), professora do Mestrado em Letras da UNICENTRO e orientadora deste trabalho.
} 
and margin and that from this margin echoes the song of mourning its Curitiba of yore. In order to corroborate the ideas presented and defended, this article presents an analysis of the short story "Cemitário de Elefantes", which allows the visualization of a shameless urban space, in ruins and in continuous transformation.

Keywords: Dalton Trevisan; Curitiba; City; Flanêur; Reading.

\section{Considerações Iniciais}

$\mathrm{O}$ século XX foi, por excelência, o século das cidades. $\mathrm{O}$ homem e a cidade se constituem, convivem e coexistem. A cidade é carrega consigo todas as alegrias, esperanças, angústias e problemas do homem perdido na multidão. Nesse sentido, a cultura da modernidade é a cultura urbana. E o escritor, que é sujeito ficcional e atento observador da cidade e sua dinamicidade, narra-a, revelando o seu esfacelamento. Ao narrar a cidade, ele mescla elementos reais à sua obra, fazendo com que a sua cidade literária desvele a cidade dos homens, que escapa às classificações e compartimentalizações. Marandola Jr. E Gratão afirmam que o escritor produz e representa o sujeito local e coletivo, pois ele possui "[...] uma voz que marca, contundentemente, a experiência de vítima em que se inserem sujeitos perdidos no movimento de uma modernidade que não garantiu sentido para as suas vidas" (MARANDOLA JR.; GRATÃo, 2010, p. 248). Por isso, a visão do escritor, traduzida em palavras, recupera a fragmentação e o esfacelamento do homem local, que se quer universal, revelando uma cidade feita de diferenças, sem cor e sem formas, opondo-se à ideia de uniformidade e de igualdade social e de pensamento.

Neste artigo apresentaremos um olhar diferente sobre a cidade, especificamente a cidade de Curitiba. É o olhar literário de Dalton Trevisan. 0 seu olhar é noturno e vampiresco. 0 Vampiro, criatura sombria, anda sorrateiramente pelo espaço urbano e contempla a crueldade do cotidiano, a periferia, emprestando sua voz à marginalidade, ao mundo torto. Ele mira o homem real, da periferia. Em sua cidade literária não há espaço para os mitos. Dalton Trevisan narra a cidade, mas não exalta as suas belezas, as suas muralhas. 0 seu canto é anti-lírico, é derrisor. Ele contempla o pão e o sangue, ou seja, as histórias cruéis que acontecem no âmbito familiar, nos fundos do Mercado Municipal de Peixes, nas rodovias que dão acesso à cidade, nos labirintos urbanos da urbe que possui um espaço periférico que ultrapassa o espaço da cidade conservado na memória coletiva e reafirmado por meio dos discursos oficiais. 
As suas narrativas apresentam uma visão negativa da cidade, utilizando a linguagem coloquial, que abre espaço para andarilhos, cafetões, prostitutas, doentes mentais e tantos outros personagens corrompidos pelo medo, nostalgia, fome, instinto sexual, miséria, que mostram o esfacelamento do indivíduo e os conflitos do dia a dia. A sua obra, portanto, é transgressora em todos os sentidos, pois fala abertamente e sem pudores de uma realidade que entra em embate com o discurso presente nos hinos, poemas, imagens e discursos. A narrativa vampiresca e despudorada dessacraliza as representações sociais, mostrando a frieza, dureza e crueldade das instituições. Poderse-á comprovar essas afirmações por meio da análise do conto "Cemitérios de Elefantes" mais a frente.

\section{Imagens e Descaminhos: A Curitiba que emerge da memória}

As cidades ideais caíram por terra, não há mais oposição entre a cidade real e a cidade divina, pois a oposição entre essas duas cidades, tema bastante amplo e trabalhado ao longo da história (A República, de Platão, Cidade de Deus, de Santo Agostinho, Utopia, de Thomas More, etc.), cedeu lugar à transitoriedade, à pluralidade e ao crescimento desordenado. A cidade é o palco da história e do progresso, é o teatro profano, onde se descortinam todas as realidades do sujeito citadino. É o labirinto onde a viagem, o canto, o amor, o sonho e a leitura entram em trânsito, em diálogo, em paródia e em contradição.

O espaço urbano, também, é espaço de visibilidade e de memória. Nesse sentido, a cidade de Curitiba, a partir da década de 1990, ficou conhecida no Brasil e no mundo como "Cidade modelo", “Capital ecológica do Brasil” e "Capital das Araucárias”, devido ao zoneamento urbano da cidade e as soluções de transporte urbano que permitiram um desenvolvimento arquitetônico planejado e harmônico no centro da cidade e seus derredores. Além disso, a cidade de Curitiba é uma das maiores do Sul do País e uma das mais ricas, com um Índice de Desenvolvimento Humano (IDH) elevado; numa escala de 0,0 a 1,0, a cidade tem um IDH de 0,856, considerado elevado e ocupando o 17ํㅡ lugar na classificação nacional, de acordo com o Caderno do Instituto Paranaense de Desenvolvimento Social (IPARDES). Por isso, é considerada uma das melhores cidades do mundo e uma das poucas no Brasil a se equiparar em desenvolvimento urbano, social 
e sustentável às cidades dos países desenvolvidos. No entanto, esse cenário perfeito esconde mazelas sociais, pobreza, medo, violência e tem todos os problemas de uma metrópole moderna. E a literatura, filha da cidade (CANDID0, 1976), inquieta e desbocada, auxilia o homem a ler o espaço urbano sem pudor.

\section{Reler e flanar pela Urbe: Novos caminhos e sentidos}

Ver o espaço urbano implica em lê-lo e imprimir-lhe sentidos, pois a leitura das imagens e dos discursos que povoam o seu âmbito é uma categoria essencial e está alicerçada nas relações sociais, de produção e no cotidiano dos sujeitos citadinos. Para Ferrara (2000, p. 126):

[...] A leitura se nutre da memória, mas seu compromisso não é histórico, é, antes, proto-histórico, porque tem o presente e o cotidiano como matrizes que, por descontinuidade, acionam uma espécie de olhar atento do presente que o instala historicamente, para produzir origens e possíveis consequências.

Essa leitura, no entanto, não deve ser homogênea e inerte, mas sim subversiva e libertária, ou melhor, uma leitura dialética, que saiba detectar a pluralidade dos discursos que constituem uma cidade, que saiba olhar para todos os lados e não somente para o centro, pois a totalidade da cidade está muito além do sentido que as autoridades e os monumentos por elas construídos oferecem aos sujeitos. Benjamin (1989) acreditava que a história oprimia o sentido original que as cidades oferecem, pois os discursos e as imagens são construídos e reconstruídos sucessivamente de acordo com o sistema e de acordo com as vontades políticas. Ferrara (2000, p. 128) afirma que a imagem é uma chave que permite ao sujeito "abrir"/"descobrir" significados preexistentes à própria imagem. As imagens do espaço urbano servem para solidificar territórios imaginários e hierárquicos, mostrando quem é quem e qual o seu lugar no espaço urbano. Por isso, as imagens sempre foram muito caras às autoridades, pois criam uma espécie de "catecismo" dogmático e autoritário, que a todo momento repetem significados e histórias. E a literatura, filha da cidade (CANDIDO, 1976), fruto do desejo e da paixão, da sabedoria e da inconsequência é a voz que não se pode abafar e ajuda a questionar o espaço urbano e as suas imagens. 
A literatura ajuda a desvendar os mecanismos que compõem o espaço urbano. Além disso, ajuda a refletir e excitar a mente do sujeito fazendo com que ele perceba o projeto no qual foi enquadrado. Acerca disso, Rama (1985, p. 98) afirma o seguinte:

Se com o passado dos campos se constrói as raízes nacionais, com o passado urbano constrói as raízes identificadoras dos cidadãos. [...] A escritura construiu as raízes, desenhou a identificação nacional, enquadrou a sociedade em um projeto [...].

Percebe-se, dessa forma, que a construção da paisagem urbana não é somente desejo da imaginação, mas é uma resposta dos sujeitos às utopias, angústias e necessidades de identificação de uma época. Rama (1985, p. 99) nos diz que a cidade real muda, destrói-se e se reconstrói sobre novas possibilidades e proposições, ao passo que a cidade das letras assimila essas imagens, trabalhando com o desejo e com a liberdade, questionando as construções da cidade real. Nesse sentido, o escritor, aquele que narra a cidade, busca a cidade escondida, o espaço urbano que foi excluído dos cartões postais, dos hinos, dos discursos oficiais. Ele busca aquela cidade que foi "reconstruída", remodelada, repaginada. O escritor flâneur vai atrás da cidade das cinzas, que emerge daquilo que é marginal e grotesco, pois ele possui o "impuro amor das cidades" (RAMA, 1985, p. 101). Esse amor impuro faz com que ele oscile entre a cidade real e a literária, exaltando o cotidiano, a dureza da vida, a liberdade perdida, as cinzas que ofuscam o ideal de beleza e liberdade propalado pelas imagens e discursos vencedores daqueles que detêm o poder.

Rama (1985) afirma que os escritores que não são cooptados pelo Poder tendem a ocupar a margem da cidade das letras e a margem da cidade real, ou seja, eles estão no limiar entre uma e outra, trabalhando com o material que estas oferecem, material esse que amiúde é o resto da cidade/sociedade, por isso causa espanto e até indignação, uma vez que se distancia do modelo tradicional. É um trabalho de revelação e despolitização da polis. É uma forma de resistência e de recuperação de imagens que fogem do nosso olhar. 0 narrador da cidade, promove a legibilidade do espaço urbano sem máscaras, sem pudores e preocupações. 


\section{Dalton Trevisan: A voz marginal que relê a cidade central}

Os discursos oficiais, segundo Sanches Neto (1998), são dissimulados, estão distantes da realidade. Nesse sentido, as críticas que a cidade das letras, por meio do olhar atento do escritor, faz à cidade de Curitiba servem para contestar as imagens de cidade linda, harmoniosa, sustentável e planejada que os poderes nos oferecem. Basta pensarmos que quando se fala em Curitiba, algumas imagens nos vêm imediatamente à mente: transporte público, sustentabilidade, Ópera de Arame, Jardim Botânico, Teatro Guaíra e Museu Oscar Niemayer (MON), o popular museu do olho, ratificando a imagem de Cidade modelo, Capital ecológica do Brasil, um nicho de desenvolvimento, uma cidade europeia perdida em meio aos trópicos.

Essa imagem sofrerá uma dessacralização por meio dos textos do escritor Dalton Trevisan. Segundo Waldman (2007), Trevisan nasceu em Curitiba no ano de 1925. Ele é um escritor que não admite concessões, ou seja, não se deixa fotografar, não dá entrevistas, não conversa com leitores, tampouco recebe prêmios. Ele criou em torno de si o mito do escritor que ninguém nunca viu, segundo Villaça (1984). Mergulhado na invisibilidade da modernidade, ele observa a vida cotidiana, os espaços esquecidos e a diminuição e a fragmentação do indivíduo. É um escritor sui generis e enigmático, à semelhança do Vampiro. Dalton Trevisan enclausurou-se em sua casa para se dedicar à escrita de contos, gênero do qual se tornou um dos maiores expoentes em nosso país. Enquanto escritor recusa a fama, os prêmios e homenagens da imprensa e das Academias. Além disso, não cede seus contatos nem mesmos a outros artistas famosos. Sua assinatura também é sui generis. Ele assina apenas "D. Trevis". Waldman (1989) afirma que, por fechar-se em sua casa, na cidade de Curitiba, e cultivar em torno de si o mito da invisibilidade e do mistério recebeu a alcunha de "Vampiro de Curitiba", que é também título de uma de suas obras.

O Vampiro de Curitiba anda pelas ruas, procurando não a luz e a beleza das imagens que a moderna Curitiba oferece, mas aquilo que está à margem, nas sombras e nas sobras da modernidade, pois ele desconfia daquilo que o discurso oficial e midiático apresenta. Trevisan é um detetive que anda por toda a parte, fazendo uso do seu incógnito, de sua invisibilidade. Em sua indolência aparente se esconde a vigilância do vampiro que não perde de vista as mazelas do sistema. Por meio da sua vigilância e 
observação atenta da realidade suburbana, Trevisan analisa cenários e personagens atípicos, tortuosos e marginais.

A intenção de Dalton Trevisan é apresentar um mundo torto, trazendo à tona os defeitos, as limitações e a marginalidade da "Cidade modelo". O Vampiro observa e se dispõe a narrar a cidade de Curitiba, a metáfora de todas as outras cidades, uma vez que por metáfora se entende a figura de palavra que opera com base numa relação de similaridade entre o sentido próprio e o sentido figurado, ou seja, a Curitiba de Dalton Trevisan é a representação de todas as cidades possíveis, permitindo a narração e a comparação. Por isso, em sua narrativa ele observa o grotesco e o marginal, o jogo entre o real e o ideal que acontece no labirinto urbano da cidade. 0 seu olhar se volta para o mundo subterrâneo e para a margem da cidade. É um olhar desviante, tortuoso. Ao Vampiro não interessa flanar pela ordem da cidade, mas sim pelo caos, pelo jogo entre violência e poder, morte e vida, pecado e redenção.

A cidade pela qual Trevisan viaja é um espaço público, uma arena social e cultural que nos é oferecida por meio da memória. Ele nos apresenta uma cidade distópica que escapa às classificações. A sua Curitiba é grotesca, cotidiana, imoral e carnavalizada. “Curitiba sem pinheiro ou céu azul, pelo que vosmecê é - província, cárcere, lar -, esta Curitiba, e não a outra para inglês ver, com amor eu viajo, viajo, viajo" (TREVISAN, 2001, p. 9). E como percebemos nas palavras do próprio Trevisan, ele ama essa Curitiba labiríntica, grotesca e babélica e não aquela que o discurso midiático nos oferece. Por isso, ele narra em seus contos histórias de pessoas desprezadas pelo sistema e pelas ideologias dominantes. Ele narra histórias de pessoas marginalizadas, "lixo da sociedade" capitalista (cf. BAUMAN, 1999). A cidade que ele nos apresenta mostra que os conflitos do dia a dia, a fome, o instinto, a miséria e a dor assolam a todos. Portanto, as imagens da sua Curitiba entram em choque com a imagem do discurso oficial, que apresenta uma cidade sem contrastes sociais e urbanos, uma joia rara do primeiro planalto do Paraná.

Trevisan ratifica com suas narrativas que as cidades ideias caíram por terra, e o que temos são cidades símbolos e fragmentadas. A cidade "é essa forma secreta, desenho invisível, forma aberta, estruturada, porém sem centro e sem fechamento. Sua leitura é travessia, passagem" (GOMES, 1994, p. 26). A Curitiba de Trevisan está para além das instituições e dos discursos. Ele desconfia das imagens e da linguagem, por isso cria a 
sua cartografia pessoal e ficcional que dessacraliza a cidade real, revelando uma cidade modelo, sustentável e preocupada com o meio-ambiente em crise, desamparada e utópica.

\section{Cemitério à margem: fome, ócio e esquecimento}

No livro Em busca de Curitiba Perdida outro texto que inquieta o leitor, causando uma náusea e um mal-estar muito grande é a narrativa intitulada "Cemitério de Elefantes", publicada em 1964 em uma obra de Dalton Trevisan de nome homônimo. A narrativa em terceira pessoa tem como ponto de partida a localização geográfica, a fim de situar as personagens e também o leitor:

À margem esquerda do rio Belém, nos fundos do mercado de peixe, ergue-se o velho ingazeiro - ali os bêbados são felizes. Curitiba os considera animais sagrados, provê às suas necessidades de cachaça e pirão. No trivial contentamse com as sobras do mercado (TREVISAN, 2001, p. 25).

Alguns elementos chamam nossa atenção e demandam uma análise mais detalhada. 0 primeiro é a expressão "à margem esquerda do rio Belém, nos fundos do mercado de peixe". A palavra margem é um substantivo feminino que denota a linha ou faixa que serve de limite para um território. Mas pode, também, significar exclusão, localidade periférica, que não é digna de atenção e, portanto, fora da lei e da cartografia da cidade. Por margem, ou melhor, marginal (por extensão) também se entende lugar desprezado onde tipos (delinquentes, marginais, mendigos e vagabundos) igualmente desprezados habitam. Na narrativa em tela, há o acréscimo do termo esquerdo à margem, rebaixando ainda mais esse lugar periférico e "sem lei", habitado por mendigos.

Segundo Chevalier (2005, p. 341), em Dicionário de Símbolos, o termo esquerdo significa a direção do inferno, ao passo que a direita aponta para o paraíso. Tal afirmação tem respaldo na tradição bíblica ${ }^{1}$. Nesse sentido, o lugar do Eleito, do defensor é à direita

\footnotetext{
1 "Olha para a direita e vê: ninguém mais me reconhece, nenhum lugar de refúgio, ninguém que olhe por mim” (Salmo 142, $5)$.

"Suscita um ímpio contra ele, que o acusador se poste à sua direita! Saia condenado do julgamento, e sua prece seja tido como pecado" (Salmo 109, 6).

"Pois ele se põe à direita do indigente, para dos juízes salvar a sua vida" (Salmo 109, 31).

"Aquele que acompanhou a destra de Moisés com seu braço glorioso, que fendeu as águas diante deles, assegurando para si mesmo renome eterno" (Isaías 63, 12).
} 
para salvar os justos dos ímpios, ao passo que os condenados à danação ficarão à esquerda. Em sua reflexão sobre o significado do termo esquerdo, Chevalier (2005, p. 341-342) afirma que uma distinção muito importante entre a direita e a esquerda acontece na Idade Média, pois o lado esquerdo, por conter o coração, passa a representar o lado feminino. Nesse sentido, a esquerda, sendo feminina, também representa a dimensão noturna e satânica, opondo-se ao lado direito que é masculino, diurno e divino. Portanto:

\begin{abstract}
Na tradição cristã do Ocidente, a direita tem um sentido ativo; a esquerda é passiva. Também, a direita significa o futuro, e a esquerda o passado, sobre o qual o homem não tem poder. Enfim, a direita possui um valor benéfico, e a esquerda parece maléfica (CHEVALIER, 2005, p. 343).
\end{abstract}

Se sairmos da esfera religiosa e mística e pensarmos no âmbito político, o termo direita só pode ser compreendido em oposição ao esquerdo, sendo a direita o lado da situação, daqueles que detêm o poder, a ordem e a hierarquia, ao passo que a esquerda representa a insatisfação, a revolução, o combate, a reivindicação e a busca constante pela justiça social e pelo respeito aos direitos do cidadão. Aqueles que optam pela esquerda no âmbito político utilizam a cor vermelha, que é carregada de simbologia, revelando o intenso amor pelas causas abraçadas, não hesitando em lutar e derramar o próprio sangue. Por isso, em termos políticos ser esquerda é arriscar-se, inovar e lutar pela liberdade e igualdade.

Em síntese, percebe-se que a direita é favorável, ordenada, tem poder e traz bons fluidos; a esquerda, por sua vez, é nefasta, maléfica, inovadora, questionadora, revolucionária, perigosa, traz má sorte e representa o caminho da morte, da danação. Ao situar as personagens na margem esquerda do rio Belém, o narrador trabalha com a ambiguidade, pois essa margem pode representar a condenação/danação imposta pela sociedade moderna a essas pobres criaturas, que não têm sonhos, apenas restos e cachaça, ou pode representar o grito marginal, revolucionário e questionador que emerge dessa margem esquerda, despossuída de qualquer assistência e visibilidade. É uma situação em que personagens invisíveis e monstruosos descortinam uma paisagem

Esses trechos bíblicos nos mostram que a direita é o lugar do defensor, daquele que tem poder e que decide sobre a vida e a morte. E é ao lado direito do defensor que os justos hão de se sentar. Portanto, a direita é sinônimo de benignidade, de vida e de retidão. 
bem distante daquela de que tanto se orgulha o curitibano. É a esquerda que representa o passado a fim de questionar o futuro, que a direita apresenta como altivo e próspero. 0 olhar insatisfeito, marginal e esquerdo do narrador apresenta o espaço onde as vítimas do sistema são sujeitos perdidos, condenados à danação, vivendo numa cidade perdida.

A morada dos tipos marginais é a margem esquerda do rio (que, ironicamente, deixa correr em seu leito a seiva da vida: a água) nos fundos de um mercado de peixe. É estratégica a localização dessa morada, pois o mercado de peixe é um lugar popular e também conhecido pela falta de higiene e pelo forte odor que os peixes exalam. É uma prática comum que nos fundos desse tipo de comércio se joguem as sobras, quase sempre misturadas ao lixo. Portanto, o lugar era, muito provavelmente, insalubre e fétido. E é lá que os bêbados, animais sagrados, habitavam. 0 narrador ressalta, ainda, que eles recebiam tratamento especial à base de cachaça e pirão. E quando este tratamento lhes faltava, apelavam para o cardápio cotidiano: o resto daquilo que não se podia mais vender, pois depois de um certo período de tempo, é comum nesses mercados a prática da "xepa", isto é, liquidar aquelas mercadorias que sobraram e possuem pequenos machucados ou estão meio ruins por um preço inferior. E somente aquilo que não serve mesmo é que vai para o lixo. E é daí que os animais sagrados retiram o seu sustento.

Esses animais sagrados vivem daquilo que lhes é oferecido gratuitamente; vivem da sobra da sociedade, não se preocupam com trabalho, regras, horários e outras questões pertinentes à agitada vida das cidades. Só se preocupam em lutar pela vida, quase que instintivamente, se a fome apertar, senão optam pela ociosidade. "Quando ronca a barriga, ao ponto de perturbar a sesta, saem do abrigo e, arrastando os pesados pés, atiram-se à luta pela vida" (TREVISAN, 2001, p. 25). Lutar pela vida significa, segundo o narrador, enterrar-se no mangue em busca de caranguejos ou esperar o vento derrubar os ingás maduros. Esses habitantes aproximam-se do primitivismo e não possuem ambições ou sonhos, apenas necessidades e instintos, o que serve, na narrativa, para questionar a cidade moderna e seus avanços tecnológicos, pois:

[...] os marginalizados da civilização (nos fundos do mercado), aqueles que não suportaram o excesso de tensão, num retorno à natureza (habitantes sob árvores) parecem aproximar-se lentamente de uma espécie de nirvana, a felicidade do nada. 0 nada do desejo" (VILLAÇA, 1984, p. 97). 
No terceiro parágrafo da narrativa, o narrador compara os bêbados aos elefantes. A figura do elefante é "a imagem viva do peso, da lentidão e da falta de jeito" (CHEVALIER, 2005, p. 359). Juan-Eduardo Cirlot, em seu Dicionário de Símbolos (1984, p. 220), por seu turno, apresenta uma outra visão do elefante que é muito interessante. Ele afirma que num sentido mais amplo e universal, os paquidermes, são símbolo de força e da potência da libido. Além disso, na Idade Média, eles eram considerados símbolos de sabedoria, temperança, eternidade e piedade.

Nesse sentido, ao comparar os bêbados com os elefantes, o narrador lhes atribui um ar grotesco, desajeitado e monstruoso, fazendo com o leitor perceba que a margem da belíssima Curitiba é habitada por personagens monstruosos, grotescos e que fogem aos padrões europeus e desenvolvidos de beleza do centro da cidade. Segundo Villaça (1984, p. 75), o grotesco em Dalton Trevisan “[...] tem caráter negativo, é às vezes formalizado, mas guarda germes de alguma coisa coletiva, de um princípio de prazer, que se mantém vivo no homem" [...]. A ideia é mostrar que aquilo que é grotesco pode se afirmar perante aquilo que é belo, sem ressentimento e sem pudor, dessacralizando uma imagem e, de certa forma, libertando-a por meio do contraste.

Há que se ressaltar que a comparação dos bêbados com os elefantes também pode enveredar por outro caminho, o da ambiguidade, pois o narrador pode estar enaltecendo a força que esses homens, excluídos e miseráveis, têm. Eles, à semelhança dos elefantes, são lentos, mas resistentes, pois a sua pele se tornou rústica, endureceu diante das agruras da vida. Vivem na ociosidade, tendo tempo para a reflexão, nada lhes incomoda. A sua imagem e a sua vida é que incomodam os que tecem a cartografia urbana. Esses homens têm as suas leis, a sua organização social e coletiva e ainda cultivam a solidariedade entre eles. É uma afronta a um mundo moderno, onde a vida frenética não tem tempo para parar, onde o ter se sobrepõe ao ser, e as pessoas nem sabem direito as causas pelas quais vivem e lutam, sendo devoradas pelo impiedoso sistema. 0 importante é nec-otium: trabalhar, produzir, consumir e ser consumido, numa eterna ciranda:

Elefantes malferidos, coçam as perebas, sem nenhuma queixa, escarrapachados sobre as raízes que servem de cama e de cadeira. Bebem e beliscam pedacinho de peixe. Cada um tem o seu lugar, gentilmente avisam:

- Não use a raiz do Pedro. 
Esse fragmento, além de revelar o grotesco de quem habita a margem da margem, desvela, também, o conformismo, a passividade e a solidariedade. Apesar de tanta miséria e abandono, ainda, existem as relações de solidariedade e de ética, uma vez que cada qual, ao seu modo, ocupa um espaço, ainda que marginal, mas ocupa e essa ocupação é digna de respeito, para que a convivência seja pacífica. 0 fato de ocupar um espaço ressoa como uma busca por uma significação social. Habito a margem esquerda do fundo do mercado de peixe, mas tenho a minha raiz, o meu abrigo, o lugar que é de minha propriedade, onde posso expressar as minhas ideias e interagir com o mundo que está ao meu redor.

A narrativa apresenta mais algumas peculiaridades como o nome dos mendigos pescadores: Pedro, João e Jonas. Pedro e João, referindo-se aos apóstolos de Jesus, pescadores e Jonas, um dos primeiros profetas, foi enviado Nínive para admoestar o povo acerca da vida fausta que viviam. Segundo o relato bíblico, ao fugir de Nínive, Jonas enfrenta uma tempestade violenta e é lançado ao mar, sendo engolido por um grande peixe. Jonas passa três noites e três dias dentro do peixe e depois se salva. Para os cristãos, a situação pela qual Jonas passa, é um prenúncio daquilo que acontecerá com Jesus. No entanto, os mendigos pescadores da narrativa, apesar de receberem o título de animais sagrados, pescam por necessidade e não por profissão, profetizam porque são excluídos e sua presença incomoda as autoridades não porque receberam o dom da profecia ou um chamado divino. E o Pedro da narrativa não é o primaz dos apóstolos que tem as chaves do céu e controla quem entra no paraíso, ele é um mísero homem que deixou a porta aberta para que todos pudessem ver os defeitos e limitações de Curitiba. Eles são, na verdade, um misto de instinto, necessidade e exclusão que povoam a flor do mangue, na margem esquerda do rio:

- Sentiu que ia se apagar e caiu fora. Eu gritei: Vai na frente, Pedro, deixa a porta aberta.

À flor do lodo borbulha o mangue - os passos de um gigante perdido? João dispõe no braseiro o peixe embrulhado em folha de bananeira.

- O Cai N'água trouxe as minhocas?

- Sabia não?

- Agora mesmo ele...

- Entregou a lata e disse: Jonas, vai dar pescadinha da boa (TREVISAN, 2001, p. 26). 
Apesar da miséria, os mendigos vivem em paz. Essa paz é garantida pela ociosidade que impera no local. 0 narrador faz questão de enfatizar isso, ao dizer que “jamais correu sangue no cemitério, a faquinha na cinta é para descamar peixe. E, aos brigões, incapazes de se moverem, basta xingarem-se à distância" (TREVISAN, 2001, p. 26). A narrativa revela como a sociedade é cruel e como esses personagens, pobres homens, não têm futuro, são restos esquecidos, esqueletos de uma sociedade fragmentada, consumista e consumidora. Os mendigos contemplam da sua margem esquerda os pescadores profissionais que mergulham seus remos, e eis que um deles faz uma oferta a um dos mendigos: "- Um peixinho aí, compadre? 0 pescador atira o peixe desprezado no fundo da canoa" (TREVISAN, 2001, p. 27). Esse breve diálogo entre o pescador e o mendigo confirma que a sociedade oferece o resto, aquilo que não serve para esses homens, resto da cidade, descartáveis, sem valor. Esses homens, mais do que sagrados são mitos da sociedade:

0 texto de "Cemitério de Elefantes" parece ser o lugar em que jazem os mitos, por já não terem serventia. Os mitos cujo objetivo é reduplicar a fala pequenaburguesia que por sua vez reduplica a do poder. Os mitos que, pretendendo promover ordem e progresso, promovem desordens internas e um progresso aparente (VILLAÇA, 1984, p. 97).

Neste cemitério de homens sem serventia e, por isso, mitológicos, não existe brigas. Talvez por isso o nome de cemitério de elefantes, pois o campo santo é o lugar da morte e também da paz. Ali todos têm seu fim último e todos se igualam. Não há destaque, ninguém é especial, todos viram pó. Assim, a narrativa não dá destaque para nenhum personagem, todos comungam da mesma miséria e todos têm o mesmo fim: beber, dormir, comer e lutar pela sobrevivência. Estão condenados à margem e à escuridão. A narrativa não possui um final, pois o leitor, ao término, não sabe o desfecho da saga dos bêbados elefantes de pés disformes e cheios de varejeiras (cf. TREVISAN, 2001, p. 26). A conclusão fica a cargo do leitor, pois o narrador encerra a narrativa dizendo que "Chico perde-se no cemitério sagrado, as carcaças de pés grotescos surgindo ao luar" (TREVISAN, 2001, p. 27). A desorientação é marcante no final da narrativa, junto com a liberdade de concluir o acontece com os mendigos marginalizados 
e esquecidos na margem esquerda do rio Belém nos fundo do mercado municipal de peixes.

\section{Considerações Finais}

As narrativas de Dalton Trevisan, em especial a que analisamos (Cemitério de Elefantes), revelam uma Curitiba imperfeita, que conjuga beleza, planejamento e desenvolvimento urbano, mas carrega a fome, a miséria e a margem. Trevisan narra o amor, o ódio e o repúdio pela cidade, que é cárcere e lar. Ele é, pois, o "Janus" moderno, que vigia a cidade, olhando em todas as suas direções, sem medo de cantar a cidade que é labiríntica, caótica, fotografia da beleza e do subúrbio miserável. Ele rompe paradigmas e expõe o homem, o espaço urbano e as tramas da modernidade, apontando para a Curitiba real, por meio da Curitiba literária.

Dalton Trevisan é uma espécie de flâneur vampiro da Curitiba Moderna que vampiriza as imagens da cidade e o discurso sobre ela. Ao andar pela cidade, narrá-la e mostrá-la, ele não contempla a beleza do cartão postal, mas aquilo que está à margem, porque é no lixo das ruas, que a sociedade despeja incessantemente e naquilo que é mais sórdido, ou seja, violência, fome, medo e sexo, que o Vampiro encontra o seu assunto preferido (cf. BENJAMIN, 1989, p. 78). Ele é o homem da multidão e, ao mesmo tempo, o vampiro invisível que escreve a partir das ruínas da sociedade. Para ele o desprezível vale ouro, é a matéria-prima.

Viajar/flanar pela Curitiba que não tem pinheirais e flores, mas dor e miséria, que é útero e túmulo, que é glória e derrota, devassidão e santidade, caos e desordem, essa é a meta daquele que vagueia invisivelmente pelo mapa urbano: o Vampiro de Curitiba, que com sua pena ágil e seu senso de leitura da cidade, mostra uma Curitiba decaída, cidade do pecado, onde os homens cedem à tentação e são expulsos do paraíso. É a cidade perdida, de homens perdidos e marginalizados onde os mitos jazem em paz.

\section{Referências}

BAUMAN, Zygmunt. Globalização: as consequências humanas. Tradução de Marcus Penchel. Rio de Janeiro: Jorge Zahar, 1999. 
BENJAMIN, Walter. Charles Baudelaire um lírico no auge do capitalismo. Tradução de José Martins Barbosa e Hemerson Alves Baptista. São Paulo: Brasiliense, 1989 (Obras escolhidas; v. 3).

BUCK-MORSS, Susan. Dialética do olhar. Walter Benjamin e o Projeto das Passagens. Tradução de Ana Luiza Andrade. Belo Horizonte-MG: Editora da UFMG/Chapecó-SC: Editora Universitária Argos, 2002.

CALVINO, Italo. As cidades invisíveis. 2a ed. Tradução de Diogo Mainardi. São Paulo: Companhia das Letras, 1992.

CANDIDO, Antonio. Literatura e sociedade: estudos de teoria e história literária. 5a ed. São Paulo: Editora Nacional, 1976.

CHEVALIER, Jean. Dicionário de Símbolos: (mitos, sonhos, costumes, gestos, formas, figuras, cores, números). Tradução: Vera da Costa e Silva [et. al]. 19a ed. Rio de Janeiro: José Olympio, 2005.

CIRLOT, Juan-Eduardo. Dicionário de Símbolos. Tradução de Rubens Eduardo Ferreira Frias. São Paulo: Editora Moraes, 1984.

COUTO, Isabel Cristina. Olhares da cidade: Curitiba e suas representações. Tuiuti: Ciência e Cultura, n. 28, FCHLA 04, p. 225-247, Curitiba, mar. 2002.

FERRARA, Lucrécia D’Aléssio. Os significados Urbanos. São Paulo: Editora da Universidade de São Paulo: Fapesp, 2000.

GOMES, Renato Cordeiro. Todas as cidades, a cidade. Literatura e experiência urbana. Rio de Janeiro: Rocco, 1994.

A cidade moderna e suas derivas pós-modernas. Revista eletrônica Semear 4 (Cátedra Pe. Antonio Vieira de Estudos Portugueses - PUC-RJ). Disponível em: http://www.letras.puc-rio.br/unidades\&nucleos/catedra/revista/4Sem 03.html.

Acesso em 22 nov. 2012.

HALL, Stuart. Da Diáspora. Identidades e Mediações. Belo Horizonte, MG: Editora UFMG, 2003.

A identidade cultural na pós-modernidade. Tradução: Tomaz Tadeu da Silva, Guacira Lopes louro. 10ª ed. Rio de Janeiro: DPeA, 2005.

MARANDOLA JR. Eduardo; GRATÃO, Lúcia Helena Batista (Org.). Geografia e Literatura. Ensaios sobre geograficidade, poética e imaginação. Londrina-PR: Eduel, 2010.

RAMA, Angel. A cidade das Letras. Tradução de Emir Sader. São Paulo: Brasiliense, 1985 (Coleção Leituras Afins). 
SANCHES NETO, Miguel. A reinvenção da Província: a revista Joaquim e o espaço de estreia de Dalton Trevisan. Tese de doutorado. Campinas-SP: UNICAMP, 1998.

TREVISAN, Dalton. Em busca de Curitiba Perdida. 6aㅡ ed. Rio de Janeiro: Record, 2001.

Cemitério de elefantes: contos. Rio de Janeiro: Civilização Brasileira, 1964.

VILLACA, Nízia. Cemitérios de mitos: uma leitura de Dalton Trevisan. Rio de Janeiro: Achiame, 1984.

WALDMANN, Berta. Do vampiro ao cafajeste: uma leitura da obra de Dalton Trevisan. $2^{\underline{a}}$ ed. São Paulo: Hucitec, 1989.

Tiro à queima-roupa. Revista Novos estudos - CEBRAP no.77. São Paulo Mar. 2007. Disponível em: http://www.scielo.br/scielo.php?script=sci arttext\&pid= S0101-33002007000100014. Acesso 24 jan. 2013

Recebido em março de 2014.

Aceito em junho de 2014. 